\title{
Os efeitos de sentido produzidos na legendagem e dublagem: o sujeito- tradutor e o processo tradutório
}

\section{The effects of meaning produced in subtitling and dubbing: the translator-subject and the translation process}

\author{
Christiano T. Santana \\ Adriana G. Conceição
}

Resumo: Este artigo coloca-se como um estudo que propõe investigar discursivamente os efeitos de sentido a partir das escolhas feitas pelo sujeitotradutor. Para tanto, baseando-nos na Análise do Discurso de linha francesa, fundada, por Pêcheux (2010), analisamos, por meio de recortes, o processo tradutório da legendagem e dublagem do filme de animação, A Nova Onda do Imperador, de 2000. É pelos recortes que discutiremos como se dão tais escolhas do sujeito-tradutor e a forma pela qual podemos pensar o sujeito-tradutor em relação com as especificidades da dublagem e da legendagem. Colocamo-nos a ponderar a

\footnotetext{
* Doutorando em Estudos de Linguagem/Linguística (UFF), mestre em Estudos de Linguagem (UFF), especialista em Língua Inglesa (PUC-Rio) e especialista em Leitura e Produção textual (UFF). Professor de Língua Inglesa no Instituto Federal do Norte de Minas Gerais e tradutor (Português<>lnglês).

Especialista em Metodologia de Ensino de Língua Portuguesa e Língua Estrangeira (UNINTER) e licenciada em Letras (Português/Inglês) (UNIPLI). Atualmente, é professora e analista de produção textual. Seus estudos voltam-se às metodologias de ensino com foco nas línguas inglesa e portuguesa.
} 
relação do sujeito-tradutor e a tradução como um processo em que nele incide uma série de implicações, como a noção de língua, sujeito e ideologia.

Palavras-chave: Legendagem; dublagem; sujeito-tradutor; análise do discurso; efeitos de sentido.

Abstract: This article is a study that seeks to investigate discursively the effects of meaning from the choices made by the subject-translator. For this purpose, based on the French Discourse Analysis, founded by Pêcheux (2010), we analyzed, through specific excerpts, the translation process of subtitling and dubbing of the movie The Emperor's New Groove, 2000. Based on these excerpts, we will discuss how some choices of subject-translator occur and the way by which we can think the subjecttranslator in relation to the specificity of dubbing and subtitling. We will strongly ponder over the relation of the subject-translator and the translation as a process in which it covers a number of implications, such as the concept of language, subject and ideology.

Keywords: Subtitling; Dubbing; subject-translator; discourse analysis; effects of meaning.

\section{Introdução}

Este artigo tem como objetivo principal apresentar o processo tradutório utilizado na legendagem e dublagem do filme de animação, $A$ Nova Onda do Imperador, produzido no ano 2000. A partir daí, se abrirá um espaço para discutirmos os efeitos de sentido produzidos (in)conscientemente pelas escolhas lexicais dos tradutores. Como exemplo, utilizaremos recortes de alguns diálogos como caminho para identificarmos mais as diferenças do que as semelhanças empregadas na legendagem e na dublagem. Não se trata, portanto, de uma abordagem quantitativa, interessam-nos o processo tradutório e a noção de sujeito-tradutor à luz da Análise do Discurso (doravante $A D$ ). Sabemos que, ao olharmos a animação de modo mais cauteloso e alerta aos detalhes, o mecanismo da legendagem e dublagem dáse de forma diferenciada, uma vez que cada uma requer especificidades 
diferentes. De um lado, a legendagem sofre restrições maiores por número de caracteres devido ao tempo e menos adaptações culturais; por outro lado, na dublagem, apesar das restrições quanto à sincronia labial, bem como do tempo e da ritmicidade das falas, há nitidamente um maior trabalho tangente às adaptações culturais e linguageiras com foco nas condições comunicativas da língua de chegada.

Este caminho de análise está embasado na $A D$ de linha francesa, fundada por Michel Pêcheux (2010), que pensa o sujeito e a língua de forma constitutiva, isto é, trata-se de uma relação não divisível - não há língua sem sujeito, e vice-versa. Pensamos o sujeito afetado pela ideologia e atravessado pelo inconsciente; em outras palavras, o sujeito - longe de ser o controlador de todos os sentidos - pensa e acredita ilusoriamente ter o domínio pleno de todos os sentidos. Porém, para ele marcar e produzir sentidos, é preciso que ele esteja nessa ilusão de total domínio da língua. 0 que acontece é que algo the escapa ao controle porque o sujeito é clivado - dividido entre o consciente e inconsciente. Portanto, o que comparecem são os atos falhos, o lapso como aquilo que the escapa na materialidade linguística.

$\mathrm{Na} A D$ nos preocupamos com um sujeito não plenamente intencional, logo descentralizado de seu total poder de manipulação de sentidos. Isso não implica que o sujeito não seja dotado de desejos, vontades, criatividade; pelo contrário, reforça o fato de que o sujeito tem sua liberdade, porém não acontece fora da ideologia que o afeta em sua própria constituição subjetiva. Deve-se, segundo Pêcheux (2010), à ideologia que engendra os sentidos por meio das práticas sociais, e o sujeito é interpelado pela ideologia, e a partir e em conjunto com esta que o mundo torna-se ilusoriamente natural e essencializado. É por meio da ideologia que se produz a ilusão e aparência de um mundo com seus sentidos estavelmente plenos e seguros.

Pensar a tradução como escopo de nossa análise na visada da $A D$ é, de algum modo, uma tentativa de trilhar caminhos outros não muito praticados no Brasil, mas já articulados por pesquisadores de grande importância na área, como Solange Mittmann, Beatriz Caldas, Giovana de Mello, apenas para citar alguns. Unir a AD como fundamento teórico e a tradução como corpus de análise torna-se, então, uma tarefa de provocação reflexiva tanto no âmbito 
analítico quanto teórico. Isso se deve ao fato de, nesta pesquisa, colocarmos em discussão as escolhas lexicais do tradutor, que não acontecem fora da ideologia, da história e, portanto, do próprio sujeito na sua posição de tradutor. Tais escolhas que não são plenamente intencionais produzem certos efeitos de sentido, e não outros.

Quando o sujeito-tradutor elege uma palavra, ele crê estar em total controle dos sentidos que circulam tal léxico; quanto a isso, Pêcheux (2010, p. 141), por sua vez, destaca que "O que oculta essa evidência, como vemos agora, é o ato de que o sujeito é desde sempre 'um indivíduo interpelado em sujeito'." Isso significa que para ser sujeito é preciso ter sido, primariamente, interpelado pela ideologia, ou seja, “a ideologia 'recruta' sujeitos entre os indivíduos (no sentido em que os militares são recrutados entre os civis) e que ela os recruta a todos" (PÊCHEUX, 2010, p. 144). Por isso que para a AD a noção do sujeito torna-se tão contundente e incontornável, uma vez que acreditamos que a ilusão de ser a origem e de ter o domínio total da língua faz parte do sujeito e é constitutivo de sua formação. Não quer dizer que o sujeito seja considerado um assujeitado e submisso à ideologia e que não tenha vontade própria, porque a ideologia também não é plena. Acreditamos que existe a resistência do sujeito para identificar-se ou não a certos sentidos, e não outros, porque "não há dominação sem resistência" e "é preciso ousar pensar por si mesmo" (PÊCHEUX, 2010, p. 281). Daí termos tais escolhas lexicais no processo tradutório como fruto ilusoriamente de uma opção autônoma do sujeito-tradutor, porém tais escolhas são produzidas por um sujeito afetado pela ideologia e atravessado pelo inconsciente - isto é, repensa-se a noção de plenitude aplicada ao sujeito e às suas escolhas -.

Com o propósito de analisarmos os recortes do diálogo em uma visada discursiva, discutiremos na seção 2.0 as especificidades da legendagem e dublagem na produção de sentido marcada pela união entre sujeito, língua e discurso, pontos estes tão caros para a AD. De forma alguma pretendemos nos aprofundar em diferentes dispositivos analíticos dessa teoria, abordaremos os que são relevantes para o presente artigo. Na seção 3.0, nos ocuparemos da análise do recorte dos diálogos tendo em vista suas duas categorias tradutórias: legendagem e dublagem. Analisaremos os efeitos de sentido 
produzidos a partir das escolhas lexicais do sujeito-tradutor para as duas categorias tradutórias, pensando-o como um negociador de sentidos, atravessado pelo inconsciente e interpelado pela ideologia. Na seção 4.0, retomaremos o trabalho feito de análise de modo que possamos pensar a dublagem e a legendagem e sua relação com o sujeito-tradutor. Com isso, aliaremos a prática tradutória e a $\mathrm{AD}$ como dispositivo analítico como auxílio para entender aquele que marca, produz sentidos de uma língua para outra: o tradutor.

\section{As especificidades da legendagem e dublagem: a produção de sentidos e o sujeito-tradutor}

O cinema tem o prestígio de ser um tipo de arte tecnológica em constante progresso, a tradução torna-se, por sua vez, em muitos países a aliada dessa arte. Em razão disso, a tradução mostra-se como um desafio, pois o tradutor precisa, principalmente, pensar nas especificidades de cada língua, no processo tradutório quando voltado à legendagem e dublagem. Entendemos que o processo tradutório implica negociação de sentido, em que o sujeito-tradutor tem a ilusão de manipular todas as escolhas lexicais, bem como dar conta dos efeitos de sentido produzidos a partir delas.

Como exemplo teórico alicerçado na crença do sujeito controlador e neutro - afastado ideologicamente de tudo o que possa lhe afetar sóciohistoricamente, Bezerra (2012), em suas reflexões, pontua para dois fatos no processo de tradução para a língua-meta: a singularidade dos múltiplos modos de ser da língua e da cultura, e também a individualidade no processo tradutório:

Vista sob esse ângulo, a tradução é um diálogo de individualidades criadoras de diferentes culturas, isto é, um autêntico diálogo de culturas, no qual o tradutor escarafuncha as entranhas do original, ausculta as vozes que o povoam, entranha-se no às vezes quase insondável da linguagem, compenetra-se da vida de suas personagens; em suma, embebe-se do original para poder interpretá-lo em seu conjunto e dar-lhe uma nova vida, vida essa, porém, marcada pela singularidade dos múltiplos modos de ser da língua e da 
cultura do tradutor, por sua individualidade criadora (BEZERRA, 2012, p. 47).

Pela perspectiva discursiva, é importante frisar que esses dois fatos destacados anteriormente não podem ocorrer e dar-se fora da ideologia constitutiva da língua-meta. A noção de singularidade do tradutor e de sua língua, bem como a tal individualidade criadora reduzem a posição do sujeitotradutor a um sujeito capaz de ter, em suas mãos, o domínio dos efeitos de sentido sobre a tradução, sobre aquilo que será entendido pelos locutores, como se o sentido estivesse colado à palavra. Bezerra (2012) considera que na recriação da imagem de uma personagem, o tradutor busca aprofundar-se integralmente no íntimo, ou seja, nas características mais significativas das personagens. Entretanto, acrescentamos que tal empenho do sujeito-tradutor é um efeito de sujeito pragmático, como diz Pêcheux (2010, p. 33), "O sujeito pragmático - isto é, cada um de nós, os 'simples particulares' face às diversas urgências de sua vida - tem por si mesmo uma imperiosa necessidade de homogeneidade lógica". Em outras palavras, perpassa na constituição do sujeito a noção de que se é possível particularizar, singularizar, categorizar de forma plena - efeito do "eu" como origem do dizer. E no processo de tradução, notamos que não se dá de forma diferente, o sujeito-tradutor tem o desejo urgente de escolher precisamente as palavras (expressões etc.), organizar, (re)estruturar o texto-meta na ilusão de criar efeitos de sentido semelhantes ao da língua-fonte. Com base em Pêcheux (2010), dizemos que o sentido está relacionado à relação do sujeito com as condições de produção, que "implicam o que é material (a língua sujeita a equívoco e à historicidade), o que é institucional (a formação social, em sua ordem) e o mecanismo imaginário" (ORLANDI, 2013, p. 40).

Pensar o fazer tradutório sugere uma relação do sujeito-tradutor afetado pela ideologia que o cerca e perpassado pelo inconsciente. E tal tradução traz em si as condições de produção, isto é, a posição do sujeitotradutor, que é marcada pelas suas escolhas conduzidas sócio-histórica e ideologicamente, mas também de forma imaginária (sujeito-tradutor escolhe certo léxico para provocar, sob efeito da ilusão, um dado sentido para o interlocutor). Os efeitos de sentido com base em suas escolhas podem ser 
mais distanciados para o interlocutor, ou não. Só há sentido pelo equívoco, isto é, o sentido sempre pode ser outro, a depender das condições de produção. O imaginário do sujeito-tradutor ao se colocar no lugar do telespectador ou do leitor da legenda é apenas um efeito, mas é da ordem do impossível. Pêcheux (2010, p. 281) destaca que "ninguém pode pensar do lugar de quem quer seja: primado prático do inconsciente, que significa que é preciso suportar o que venha a ser pensado".

É importante pôr em relevo que a relação da legendagem e da dublagem com o tradutor não se dá apenas no âmbito da (re)estruturação da língua-fonte para a língua-meta. Rónai $(2012$, p. 41) reforça que "O TRABALHO DO TRADUTOR passa por um caminho ladeado de armadilhas". Conduzidos por esta afirmação, discutiremos as particularidades técnicas da legendagem e da dublagem. Podem-se encontrar na legendagem duas limitações básicas: a restrição do número de caracteres que aparecem na tela e o tempo disponível necessário para a leitura. Koglin (2008, p. 10) corrobora a respeito das limitações e especificidades técnicas da dublagem:

Os legendadores realizam a tradução condicionados a algumas normas, tais como: limite de tempo - tanto de exposição da legenda na tela quanto de prazo para entrega da tarefa -, número de caracteres e de linhas pré-estabelecido, e sincronia entre imagem [som] e legenda. Além disso, os tradutores de legendas precisam lidar com a censura imposta pela distribuidora, que pode exigir que eles omitam ou abrandem enunciados com críticas, substituam palavras agressivas ou minimizem vocábulos obscenos.

Nota-se outro aspecto ressaltado na produção da legenda que se refere a uma redução dos elementos linguístico-semânticos ocasionados pelo tempo de leitura. Gorovitz (2006, p. 65) explica esta característica ao declarar que "O tradutor, pelas limitações técnicas impostas, deve resumir e sintetizar ao máximo o diálogo, tentando produzir uma mensagem curta e clara e tendo unidade semântica". Sob essa demanda dentro do mercado da tradução, esse procedimento reforça a ilusão de autonomia do tradutor sobre a língua - os cortes, as reduções, as omissões de enunciados ou brandamentos na linguagem. Isto é, o que legitima, a princípio, o fazer do tradutor é a sua autonomia sobre as palavras e sobre a recombinação sintática. Se olharmos 
mais de perto, há nesse fazer tradutório uma autonomia legitimada pelas agências e editoras. É preciso pensar que a relação do sujeito com a língua é ideológica. As escolhas de palavras, os cortes, as omissões, as restrições são efeitos de um sujeito, atravessado pelo institucional engendrado pela ideologia, que tem em sua constituição a necessidade por uma unidade completa de sentido. Como nos diz Orlandi (2007, p. 19), "Essa ilusão de unidade é efeito ideológico, é construção necessária do imaginário discursivo. Logo, tanto a dispersão como a ilusão da unidade são igualmente constitutivas".

O funcionamento da língua se dá pelo "não dizer" também, fundamento este que produz o sentido. Dizemos algo para não dizermos (ilusoriamente) de outra forma, assim circula-se o sentido, ou seja, por intermédio da incompletude. Quando o sujeito-tradutor (in)conscientemente elege certas palavras, produzem-se sentidos que não estão fechados em si. Tal incompletude é fundante para o sentido, mesmo que para o sujeitotradutor sua escolha seja completa e plena - ilusão constitutiva do sujeito. Como aponta Orlandi (2007, p. 47), "É a incompletude que produz a possibilidade do múltiplo, base da polissemia".

Com um olhar para o processo da dublagem, atualmente verifica-se que diversas categorias de filmes, classificadas para o público adulto, tais como filmes de ação, drama e suspense, são oferecidas aos espectadores em versões legendadas e dubladas, com vistas à democratização. Entretanto, a título de exemplificação, quando se trata do público infantil, em que se predominam os desenhos e animações, a dublagem ganha espaço pelo tipo de linguagem, assim como pelo tipo de público em específico.

Se na legendagem são encontradas algumas "armadilhas" para o tradutor, o mesmo acontece com a dublagem. Muitos são os desafios vistos na técnica da dublagem, entre eles estão a interpretação dos atores, pois o texto precisa ser dito com muita naturalidade, com sincronia do movimento labial e com a preocupação constante com os movimentos corporais do ator. Vale ressaltar, também, outro aspecto no processo tradutório para dublagem. 0 dublador utiliza a criação, ou seja, a adaptação produzida pelo tradutor do script original para a língua de chegada. Pode-se observar que os dubladores 
enfrentam muitas dificuldades com esta técnica, o que demanda muita dedicação e trabalho. Para embasar teoricamente essas dificuldades técnicas pertinentes ao processo de dublagem, Lessa (2002, p. 72) comprova que:

\begin{abstract}
As pessoas geralmente pensam que a dublagem só consiste em ir para o estúdio e "correr atrás da boca" de artista estrangeiro. Pois ela envolve todo um processo que começa com a chegada da fita com a produção a ganhar vozes nacionais na empresa dubladora, passando por vários estágios até chegar ao produto final para a distribuição no mercado.
\end{abstract}

Os vários estágios deste processo têm grande importância, pois resultam na maneira como os efeitos de sentido são produzidos e marcados. A base desta técnica fica por conta da linguagem oral reproduzida na interpretação dos atores ao despertar o prazer da audição que ultrapassa a tecnicidade da leitura. A oralidade cria um laço com o espectador. Sendo assim, ao dublar um filme, os diálogos não podem, de modo algum, soar como um texto (script) lido, isto é, perder a naturalidade, pois de acordo com Perini (2004, p. 68), “Nós não conseguiríamos falar como escrevemos, porque isso sobrecarregaria nossa memória a ponto de inviabilizar a construção do texto e, por motivo análogo, nosso ouvinte não conseguiria nos entender".

De modo geral, a desenvoltura das traduções audiovisuais no Brasil tem avançado, o que contribuiu para a fama da dublagem brasileira no mundo, porém todo este destaque se deve também à colaboração de quem traduz. Os procedimentos técnicos da legendagem e dublagem são muito específicos e distintos entre si. Em outras palavras, enquanto na legendagem há a visualização global do filme, as tomadas de notas, a extensão das linhas, a sincronização e, por fim, a edição das legendas; na dublagem, há a percepção da atuação dos atores do filme, a leitura do roteiro e do diálogo, a interpretação dos dubladores, os movimentos labiais, a adequação da fala e a entoação da voz de acordo com os movimentos corporais, a sincronia e pausa das falas, entre outros. Existem, por sua vez, em conjunto com a língua, as diretrizes voltadas às técnicas de dublagem e legendagem que se caracterizam por ser uma política de cerceamento, de silêncio, de restrição. E isto é também natural da língua. De fato, são peculiaridades desse fazer tradutório; é preciso, entretanto, ter em mente que as escolhas do sujeito- 
tradutor não se dão apenas a partir de tais restrições. A língua é falha e incompleta, no sentido de que a incompletude do sentido é a possibilidade para produção de um sentido outro.

Precisamos pôr em reflexão que o sujeito constitutivamente se dá também em meio à resistência, o sujeito-tradutor pode (ou não), de forma (in)consciente, marcar sentidos que podem ir de encontro com as políticas de cerceamento ou as próprias restrições da técnica. Não podemos pensar isso como uma incapacidade do tradutor de atender às tecnicidades do processo de legendagem e de dublagem, mas como um movimento de não identificação (in)consciente do sujeito-tradutor com certos sentidos do texto-fonte. Tal movimento não é plenamente consciente, e aí que entra a noção da língua como efeito de sentido. Não escolher uma forma de dizer na tradução não implica apenas uma escolha plenamente consciente (sem a manifestação do inconsciente), sugere também a relação do sujeito-tradutor com a língua, que se dá pela resistência (escolher para dizer de uma forma, porém os sentidos (he escapam), assim como pela afetação ideológica e sócio-histórica. Pêcheux (ibidem) nos assevera que "Não há dominação sem resistência: primeiro prático da luta de classes, que significa que é preciso 'ousar se revoltar'." Tal resistência é constitutiva do sujeito, pois ele não é um ser assujeitado, é afetado pela ideologia (que é um ritual ideológico também com falhas), que funciona como um mecanismo de essencialização e naturalização do mundo, e atravessado pelo inconsciente, que opera no sujeito a possibilidade da dúvida, da falha, da ilusão constitutiva de ser a origem do dizer e manipulador pleno dos sentidos.

Com isso em vista, passaremos para próxima seção pensando o sujeitotradutor como produtor e negociador de sentido que ilusoriamente crê, de algum modo, se isentar e se distanciar de suas escolhas lexicais e da produção dos efeitos de sentido.

\section{Análise dos diálogos}

Para a análise dos diálogos escolhidos para este artigo, selecionamos alguns trechos extraídos do filme, categorizado como animação, $A$ Nova Onda TradTerm, São Paulo, v. 31, Março/2018, p. 4-24 
do Imperador (2000). Utiliza-se como corpus para este trabalho a versão da animação em DVD, comercializada em lojas especializadas de todo Brasil e disponível com áudio e legendas em inglês, português e espanhol.

Será aplicada a opção de áudio em inglês (áudio original do filme) e legendas em português para uma primeira análise e, em um segundo momento, a opção de áudio e legendas em português. Vale ressaltar que, na época em que o filme foi exibido, a maioria dos telespectadores brasileiros poderia optar, democraticamente, por assistir a cópias dubladas ou legendadas.

Seguiremos a analisar os efeitos de sentido produzidos a partir das escolhas do sujeito-tradutor nos recortes propostos. 0 sujeito-tradutor, por ser um sujeito social, marca sentidos constituídos sócio-histórica e ideologicamente de forma (in)consciente. Isto é, o sujeito não dá conta de controlar todos os sentidos, apesar de a noção de totalidade ser o desejo constitutivo do sujeito. Ademais, só há sentido porque está dentro do jogo da língua, para a $A D$ não há significado imanente. Portanto, encaramos 0 processo tradutório como uma construção de sentido que não pode, nem deve pretender-se, buscar equivalências de sentidos com o original, como apregoada por Nida (1982), com sua equivalência formal e dinâmica. Os sentidos, por sua vez, são produzidos porque há uma relação entre sujeito, língua, ideologia e discurso que se manifestam de maneira imbricada e constitutiva.

\subsection{Análise comparativa dos diálogos: um olhar para os efeitos de sentido no processo tradutório}

Voltemos inicialmente à descrição da história para seguirmos em direção à análise. Kuzco é o nome do protagonista da animação, um presunçoso imperador que é transformado, por engano, em lhama pela perversa conselheira Yzma. Após ter sido dispensada de seu cargo, Yzma tem a intenção de matar o imperador e assumir seu império junto com Kronk, seu fiel "esperto" comparsa, que envenenaria o imperador, porém o conteúdo do 
frasco não continha veneno e, sim, extrato de lhama. Yzma manda Kronk matar Kuzco, mas ele perde a coragem e o imperador acaba desaparecendo. Até que perdido em uma floresta, Kuzco conta com a ajuda de um simples camponês chamado Pacha para tentar recuperar sua forma humana e seu trono. Essa jornada resulta na criação de um laço transformador: a amizade.

No diálogo a seguir (trecho: 45min05s), Yzma e Kronk estão perdidos em uma floresta à procura de Kuzco, já transformado em lhama, com a intenção de eliminar de vez o imperador. Kronk carrega Yzma em uma pequena barraca, como se fosse uma mochila em suas costas. Yzma grita e reclama o tempo todo, ao sair da barraca ela encontra um esquilo que the oferece uma noz. Ela grita com o inofensivo animal (estava se abrigando com o amigável Kronk) que só tentava ser gentil. 0 esquilo e Kronk iniciam uma conversa, e Yzma pergunta se ele está falando com o esquilo, Kronk confirma e, assim, segue a fala da personagem:

\begin{tabular}{|l|l|l|}
\hline \multicolumn{1}{|c|}{$\begin{array}{c}\text { Áudio Original } \\
\text { (Inglês-EUA) }\end{array}$} & \multicolumn{1}{|c|}{ Legenda } & \multicolumn{1}{c|}{ Dublagem } \\
\hline $\begin{array}{l}\text { I was a Junior chipmunk, } \\
\text { uh... and I had to be } \\
\text { versed in all the woodland } \\
\text { creatures. }\end{array}$ & $\begin{array}{l}\text { Fui do Clube Juvenil } \\
\text { dos Esquilos. Eu tive de } \\
\text { aprender sobre todas as } \\
\text { criaturas silvestres. }\end{array}$ & $\begin{array}{l}\text { Eue eu já fui } \\
\text { lobinho, uh... Tinha } \\
\text { com as criaturas da } \\
\text { floresta. }\end{array}$ \\
\hline
\end{tabular}

Nesse trecho, pode-se inferir que a personagem Kronk era membro de uma irmandade ou clube, no qual ele teria de aprender a passar por situações adversas, isto é, ter certo expediente. 0 fato de ele compreender a linguagem do esquilo nos mostra a facilidade em resolver a questão em meio à barreira da comunicação, o que provoca um efeito de humor.

Há um ponto pertinente para discutirmos sobre esse trecho do diálogo: a diferença de escolha na legenda e na dublagem quanto à tradução da sequência "I was a Junior chipmunk". Na legenda, por exemplo, a tradução cunhada é "Fui do Clube Juvenil dos Esquilos". A noção de "clube juvenil" traz o sentido de recreação e diversão para crianças e pré-adolescentes; entretanto, a escolha dessa tradução não se dá de forma aleatória. 0 sujeito- 
tradutor ao eleger tal expressão busca ilusoriamente a precisão do significado e, ao mesmo tempo, uma equivalência de sentido com a língua-alvo. Essa escolha não é plenamente consciente, pois é atravessada por sentidos ideologicamente construídos, que se dão em meio a possíveis deslocamentos. A expressão "clube juvenil" não é um termo altamente reconhecido se formos levar em conta o leitor da legenda (por tratar-se de um grupo infantil). Sob a ilusão de ser origem do dizer, o sujeito-tradutor crê que sua escolha dá conta dos sentidos que circulam a expressão "clube juvenil", por ser composta de duas palavras de fácil compreensão. Precisamos frisar que "As palavras simples do nosso cotidiano já chegam até nós carregadas de sentidos que não sabemos como se constituíram e que no entanto significam em nós e para nós" (ORLANDI, 2013, p. 20), e tais sentidos significam porque neles incide a história. Portanto, escolher (in)conscientemente uma palavra por outra implica trazer à tona sentidos que historicamente não damos conta, e seus efeitos de sentido podem ser sempre outros.

Como vimos, a opção por "clube juvenil" evoca sentidos de uma época mais antiga do que a própria produção do filme, datada do ano de 2000. Apesar de a expressão ser de fácil inferência, sabemos que a legenda para o público infantil é praticamente um recurso apagado, uma vez que nessa faixa etária a dublagem torna-se a ferramenta mais utilizada. Acabamos lendo termos, por vezes, menos idiomáticos ou longe da adequação de público, porque o sujeito-tradutor traz em si uma memória de que a legendagem deve ser seca, direta, sem rodeios ou melhoramentos linguísticos.

Essa noção de total autonomia sobre a língua provoca no tradutor a crença de que suas escolhas lexicais causarão um sentido apenas. Porém, a história, a ideologia e a língua de forma imbricada determinam as escolhas do sujeito-tradutor; portanto, a escolha da expressão "clube juvenil" é perpassada pela ideologia, porque "Para que minhas palavras tenham sentido é preciso que elas já façam sentido" (ORLANDI, 2013, p. 33).

O sentido de "clube juvenil" vem construído historicamente no Brasil desde o início do século XX como o maior clube de recreação em Caxias do Sul, município do estado do Rio Grande do Sul. A palavra carrega sua historicidade, e seus sentidos podem circular mais fortemente em um dado 
momento histórico. Ao trabalhar com esse termo na tradução da legenda, os efeitos de sentido se marcam em meio à equivocidade da língua, isto é, tais sentidos para leitores de outras regiões e estados - se não tiverem o conhecimento dessa expressão baseada em sua história - o sentido se produz de outra forma, como possivelmente um lugar em que crianças se unem para brincar e se divertir, mesmo que tal expressão, para alguns, produza certo estranhamento.

Enquanto isso, na dublagem, há o termo traduzido como "lobinho", que nos remete à categoria de escoteiros entre seis e dez anos. O lobo foi o animal escolhido para representar o grupo de escoteiros por ser um animal inteligente que sabe viver em grupo. Neste caso, acreditamos que a escolha do sujeito-tradutor seja pelo fato deste grupo adaptar-se às circunstâncias, assim como a personagem. Como se trata de uma animação e de o públicoalvo, em sua maioria, ser de crianças, a expressão pode também causar estranhamento. Tal escolha é pensada e, de certo modo, arquitetada pelo tradutor que tem a preocupação com a adequação, fluidez, ritmicidade fatores estes que cercam o processo tradutório -. Logo, as condições de produção do sujeito-tradutor se dão em meio a essas restrições. Como exemplo, as adaptações culturais e os melhoramentos podem, em alguns casos, se perder porque um filme não apresenta a característica de digressão explicativa para o espectador.

De toda forma, é necessário pensar que todo e qualquer sentido da e na língua é produzido em meio a certas condições de produção. 0 sujeitotradutor escolhe as palavras que o fisgam sócio-histórica e ideologicamente, porque "Ao falarmos nos filiamos a redes de sentidos, mas não aprendemos como fazê-lo, ficando ao sabor da ideologia e do inconsciente" (ORLANDI, 2013, p. 34). Entretanto, o sujeito-tradutor pensa que tais escolhas partiram estritamente dele, de forma autônoma. Cada sujeito é afetado pelo sentido de uma dada forma, "Fica por conta da história e do acaso, do jogo da língua e do equívoco que constitui nossa relação com eles [os sentidos]" (ibidem.)

No próximo diálogo (trecho: 48min47s), Kronk está conversando com Yzma em um restaurante e Pacha está sentado ao lado da mesa deles, enquanto Kuzco, disfarçado de mulher, vai até a cozinha reclamar das opções 
do cardápio. Yzma, com raiva, quebra o garfo e Kronk prontamente pergunta a Pacha se ele pode emprestar o que está à mesa. É nesse momento que ele pergunta: "Eu conheço você?" E o diálogo continua:

\begin{tabular}{|c|c|c|}
\hline Áudio Original (Inglês-EUA) & Legenda & Dublagem \\
\hline Wrestled you in high school? & $\begin{array}{c}\text { Lutei com você no } \\
\text { colegial? }\end{array}$ & $\begin{array}{c}\text { É da aula de } \\
\text { capoeira? }\end{array}$ \\
\hline
\end{tabular}

No áudio original, a palavra high school foi utilizada para situar um período da educação americana referente à segunda fase da escola secundária, de modo que podemos compará-la com a fase do ensino médio na educação brasileira. No entanto, é bem verdade que, em grande parte da educação pública do Brasil, tanto no ensino fundamental quanto no médio, muitos sequer sabem o significado, o que levanta uma questão peculiar na aplicação da legenda.

O tradutor da legenda utilizou a palavra "colegial" na ilusão de fazer uma correspondência com a palavra high school, o significado aparentemente da língua-alvo alcança o da língua-fonte. A escolha do termo "colegial", porém, nos remete aos tempos antigos, ao ano de 1961 quando foi aprovada a Lei $n^{\circ}$. 4.024, que estabelecia as diretrizes e bases da educação nacional. Posteriormente, adveio a terminologia "Segundo Grau" com a reforma do sistema educacional em 1971 quando foi criada a Lei no. 5.692/7. Este processo de modificação organizou o sistema educacional da seguinte maneira: a escola primária e o ginásio foram fundidos e denominados de ensino de primeiro grau, enquanto o antigo colegial passou a ser chamado ensino de segundo grau. Acredita-se que "Segundo Grau" seria mais atualizado para o ano de lançamento, 2000, e adequado e mais significativo à língua-alvo. Vale ponderar que, no ano da exibição do filme, já estava em vigência o termo "Ensino Médio", mas circulava fortemente ainda o termo "Segundo Grau". De todo modo, interpretamos a escolha "colegial" do sujeito-tradutor como uma forma de posicionar e caracterizar tais personagens como mais velhos - personagens que estudaram à época, em que Ensino Médio era ainda chamado de colegial. 
Na dublagem, foi feita uma adaptação, pois os vocábulos high school e "colegial" não possuem relação alguma com o termo "aula de capoeira". Analisamos que não houve apelo de imagem que incitasse o uso da expressão "aula de capoeira" no processo tradutório. Essa expressão partiu singularmente da perspectiva do sujeito-tradutor, pois não há motivação visual para tal adaptação. Reconhece-se que no processo de dublagem a oralidade se mostra como um aspecto significativo, enquanto a adaptação como um artifício, de modo que o público-alvo possa ser conduzido com mais desenvoltura e familiaridade na interpretação de um termo concernente a um esporte tão popular no Brasil. Em suma, tal escolha marca um efeito de sujeito-tradutor ilusoriamente conduzido pela crença da criatividade como efeito de liberdade na linguagem.

Na continuação da próxima cena (trecho: 48 min47s), Kronk permanece interessado em saber de onde conhece Pacha e, assim, segue o diálogo:

\begin{tabular}{|l|l|l|}
\hline Áudio Original (Inglês-EUA) & \multicolumn{1}{|c|}{ Legenda } & \multicolumn{1}{|c|}{ Dublagem } \\
\hline $\begin{array}{l}\text { Oh, I got it. Miss Narca's } \\
\text { interpretative dance, two } \\
\text { semesters. }\end{array}$ & $\begin{array}{l}\text { Já sei. Aula de dança } \\
\text { interpretativa com a a sei. Lambada } \\
\text { senhora Narca, dois } \\
\text { semestres. }\end{array}$ & $\begin{array}{l}\text { Já Chiquinho de } \\
\text { Jesus, do dois } \\
\text { semestres. }\end{array}$ \\
\hline
\end{tabular}

Observa-se o tom cômico ao imaginar um rapaz com a estrutura física de Kronk, alto e másculo, fazendo aula de dança interpretativa. O que provoca o efeito do humor é justamente o inesperado resultante da surpresa provocada nas pessoas, uma vez que para produzir o riso, o filme precisa da coparticipação do espectador. O sentido do filme original enfatiza a personalidade eclética de Kronk. A característica autêntica da personagem é passada para a língua-alvo de forma concisa.

A tradução da legenda marca um sujeito-tradutor que busca, ilusoriamente, manter o sentido do original. Seu processo tradutório se apoia na crença de que tradução ideal é aquela que replica sentidos determinados na língua-fonte. Gorovitz (2006, p. 66) corrobora ao dizer: “[...] é preciso que a tradução se estabeleça em adequação com o contexto geral do filme e 
mantenha com ele uma relação contínua". Em outras palavras, o sujeitotradutor da legenda se atenta à cópia de estruturas a partir do original, não leva tanto em conta a adequação de sentidos da língua-alvo. Vemos, então, na legenda uma tradução marcada pela crença de um sujeito-tradutor que busca restringir os sentidos a partir da língua-fonte. Ilusoriamente pensa que, ao replicar estruturas próximas ao original, ele está próximo a um sentido mais eficaz.

$\mathrm{Na}$ visada discursiva que assumimos, é importante observar que a tradução da legenda mantém um distanciamento maior com seu público-alvo, uma vez que o termo “dança interpretativa” carrega um sentido formal da linguagem. Tal formalidade é produzida pelo sujeito-tradutor que não pensa profundamente na possibilidade de adaptações. Marca-se um sujeito-tradutor com uma visão de tradução mais tradicional, que toma o texto original sem ao menos recorrer a outras possíveis formas de dizer na língua-alvo.

$\mathrm{Na}$ tradução aplicada à dublagem, valem ressaltar dois pontos importantes: foram atribuídos outro tipo de dança e outro nome ao professor de dança, diferentemente do sentido original; isto abre espaço para uma nova concepção. Paes afirma ser:

Louvável, na verdade, há de ser a tradução que, sem desfigurar por imperícia as normas correntes da vernaculidade, deixe transparecer um certo quid de estranheza capaz de refletir, em grau necessariamente reduzido, as diferenças de visão de mundo entre a línguafonte e a língua-alvo (PAES, 1990, p. 106).

Foi utilizado na dublagem um tipo de dança muito conhecido na cultura-alvo, principalmente no final dos anos 80, a lambada. É bem verdade que, no ano 2000, época da reprodução do filme, a lambada, que teve seu auge ao final dos anos 80 e início de 90 , já havia perdido seu destaque, porém pertence ainda ao imaginário coletivo de nossa cultura. Outra questão singular é a mudança do nome do professor de dança para "Chiquinho de Jesus”. No Brasil, por haver um professor de dança muito famoso chamado “Carlinhos de Jesus”, entendemos que, para evitar problemas com direitos autorais, ou para fazer uma homenagem indireta ao professor, o tradutor tenha criado o nome "Chiquinho de Jesus". A busca pelo efeito de humor é 
feita a partir do conhecimento partilhado na cultura da língua-alvo. Para a criação do tom cômico no original, ocorre a substituição da personagem, Miss Narca, por Chiquinho de Jesus, para atender culturalmente à língua-alvo.

Com base nesses recortes, no âmbito da dublagem, as escolhas de palavras produzem sentidos outros na tradução, ou seja, o sujeito-tradutor da dublagem está preocupado com o processo criativo e com o público-alvo no que se refere à escolha lexical. Tais palavras marcam um sujeito-tradutor que busca repensar a cultura-alvo, assim como intenta manter mais distância de uma tradução truncada ou muito próxima da estrutura da língua-fonte. As escolhas lexicais apontam para um sujeito-tradutor que, entre erros e acertos, crê ilusoriamente que suas escolhas lexicais vão produzir uma dada naturalidade na língua-alvo. Mas percebemos que, mesmo com mudanças no léxico, sendo elas cabíveis ou não, o nível sintático permanece dialogando fortemente com a língua-fonte. Entendemos que tais escolhas lexicais - ou a falta delas - se dão principalmente em virtude do sincronismo labial, que, de algum modo, acaba por ser um meio de restringir ou silenciar certos sentidos.

\section{Considerações finais}

A principal proposta deste estudo é apresentar a análise dos diálogos como elo entre os processos de legendagem e dublagem de um filme em língua inglesa traduzido para a língua portuguesa do Brasil. A partir disso, pensarmos a produção de sentido marcada pelas escolhas lexicais do sujeitotradutor, que não se dão fora da ideologia e do escopo sócio-histórico. Escolher não é apenas restringir sentidos, mas o próprio ato de escolher já é perpassado pela perspectiva sócio, histórico e ideológico. Daí entendermos que a produção de sentido não parte somente da escolha do sujeito-tradutor, que está sob a ilusão de ter total controle sobre palavras e sentidos.

Observamos que legendagem e dublagem têm, como característica própria, o corte, o silenciamento, a vigilância de certos sentidos a partir da possibilidade entre o texto na legenda (em virtude à restrição espaço-tempo) e o sincronismo labial aplicado à dublagem. Com isso, reforça-se, constitutivamente, o suposto controle do sujeito-tradutor para estabelecer TradTerm, São Paulo, v. 31, Março/2018, p. 4-24 
certas escolhas lexicais. E isso é importante, pois é por meio dessa crença que o sujeito é capaz de produzir e buscar delimitar certos sentidos. Entretanto, tais sentidos escapam, porque o sentido não está na palavra (ORLANDI, 2013), é constituído sócio-histórica e ideologicamente, e dependerá de qual condição de produção em que tal dizer se manifesta.

$\mathrm{Na}$ análise, percebemos alguns movimentos importantes que precisam ser estudados mais profundamente em nossas próximas pesquisas. Há o fato de a escolha do sujeito-tradutor ser determinada histórica e ideologicamente, assim como as possibilidades da posição sujeito-tradutor na legendagem e na dublagem. Pelo que vimos em nosso recorte, o sujeito-tradutor na legendagem tende a marcar uma posição mais tradicional de tradução e mais rígida. Levantamos a hipótese de que se trata da restrição de caracteres, porém precisamos repensar essa questão, uma vez que a estrutura da tradução mostrou-se muito próxima à língua-fonte. Isso acabou por demonstrar que o sujeito-tradutor da legenda não estava apenas preocupado com a quantidade de caracteres, mas também com a noção ilusória de literalidade e fidedignidade no processo tradutório (crença esta fortalecida pela perspectiva tradicional da tradução).

Baseando nossa investigação nos recortes utilizados como prática analítica, quanto ao sujeito-tradutor da dublagem, notamos que há uma preocupação maior com a criatividade (que entendemos como um efeito de sentido). Há um acordo praticamente tácito (ou melhor, diríamos efeito ilusório da linguagem) de que na dublagem existe um espaço para criatividade e maiores adaptações. Nesse caso, o sujeito-tradutor mostrou-se, por vezes, imerso nesse discurso da criatividade apenas. De todo modo, é necessário ponderar que tal criatividade, como um efeito ilusório de sentidos, se dá pela escolha do sujeito-tradutor, mas determinada ideológica e sóciohistoricamente. Apesar de o sujeito-tradutor marcar certos sentidos que tendem a uma posição sujeito-tradutor de uma perspectiva tradutória de linha contestadora, ainda produz (in)conscientemente a partir de uma estrutura sintática ditada pela língua-fonte. Sabemos da questão do movimento labial, entre tantas outras implicações da dublagem, mas é importante estudarmos que o sentido produzido por um dado dizer, e não outro, marca a posição do 
sujeito. Além disso, abre-se caminho para pensarmos que o processo tradutório não é resultado de um sujeito-tradutor filiado estritamente a uma perspectiva de tradução.

Incidem no sujeito-tradutor não só escolhas de palavras, apesar de sua posição ser legitimada também para isso, como também a complexa tarefa de lidar com os detalhes demandados da legendagem e dublagem. Isso porque sua posição como sujeito-tradutor para cada técnica já é cerceada por regras e restrições. Vale enfatizar que temos em todo esse processo um sujeito, independentemente de sua posição de tradutor ou não, que, para escolher um dizer, deverá deixar de dizer de tantas outras formas possíveis (ORLANDI, 2013). Isto é, o sujeito-tradutor escolhe um dizer sob a crença ilusória de que tais escolhas partem dele apenas, e não de uma conjuntura ideológica, social e histórica.

Com isso em vista, neste estudo buscamos pensar o tradutor na visada discursiva em diálogo com o processo tradutório. Para isso, é necessário levantar questões que girem em torno da noção de sujeito, língua, ideologia e discurso. Tal estudo nos mostra como um caminho possível de análise porque pensar o tradutor e a tradução como um processo ideológico, histórico em que a língua se constitui a partir e para o sujeito. Unir a $A D$ e o estudo da tradução torna-se um terreno fértil, pois é necessário ir além da noção da tradução de linha tradicional ou contestadora, fidelidade ou infidelidade, equivalência ou correspondência. Precisamos nos colocar a pensar na tradução para além de dicotomias reducionistas assim.

\section{Referências bibliográficas}

A Nova Onda do Imperador. Direção: Mark Dindal. Produção: Randy Fullmer. EUA: Estúdios Walt Disney Pictures, 2000. 1 DVD (78 MIN).

BEZERRA, Paulo. A tradução como criação. Estudos Avançados/Universidade de São Paulo. Instituto de Estudos Avançados. Volume 26. Número 76. São Paulo: IEA, 2012.

BRASIL, Sistema Educativo Nacional de. Disponível em: <http://www.oei.es/quipu/brasil/historia.pdf> - Acesso em: 14 de fevereiro de 2014. 
GOROVITZ, Sabine. Os labirintos da tradução: a legendagem e a construção do imaginário. Brasília: Universidade de Brasília, 2006.

KOGLIN, Arlene. A tradução de metáforas geradoras de humor na série televisiva $\mathrm{Fr}$ i e $\mathrm{n} d \mathrm{~s}$ : um estudo de legendas. 2008. 99f. Dissertação (Mestrado em Estudos daTradução). Universidade Federal de Santa Catarina, Florianópolis.

LESSA, L. P. A dublagem no Brasil. Juiz de Fora, 2002. 289f. Trabalho apresentado na disciplina Projetos Experimentais (Graduação em Comunicação Social) - Faculdade de comunicação, Universidade Federal de Juiz de Fora, Juiz de Fora, 2002.

ORLANDI, E. Interpretação, autoria, leitura e efeitos do trabalho simbólico. $5^{\mathrm{a}}$. Ed. Pontes, Campinas, 2007.

. Análise de discurso. Princípios e procedimentos. 11ª . Ed. Pontes, Campinas, 2013.

PAES, José Paulo. Tradução: a ponte necessária. Aspectos e problemas da arte de traduzir. São Paulo: Atica/Secretaria de Estado e Cultura. 1990.

PÊCHEUX, M. Por uma análise automática do discurso: uma introdução à obra de Pêcheux. Em GADET, F. \& HAK. Trad. Bethânia S. Mariani [et al]. Editora Unicamp, Campinas, 4ª. Ed. [1969/2010].

PERINI, M. A. A língua do Brasil amanhã e outros mistérios. São Paulo: Parábola, 2004.

RÓNAI, Paulo, 1907-1992. A tradução vivida. Rio de Janeiro: $4^{\mathrm{a}}$ ed. José Olympio, 2012. 